\title{
Dystonia after striatopallidal and thalamic stroke: clinicoradiological correlations and pathophysiological mechanisms
}

\author{
P Krystkowiak, P Martinat, L Defebvre, J P Pruvo, D Leys, A Destée
}

\begin{abstract}
Objective-To establish the pathophysiological mechanisms of striatopallidal and thalamic dystonia.

Methods-Five patients from among 26 who presented (between March 1987 and July 1996) with focal dystonia, segmental dystonia, or hemidystonia caused by a single localised vascular lesion, were selected. Patients with lesions with indefinite boundaries, and diffuse, or multiple, or large brain lesions were excluded. Three dimensional T1 weighted MRI (1.5 tesla) was performed to determine the topography of the lesions. The atlas of Hassler allowed the stereotactic localisation of the lesions to be specified exactly.

Results-Three patients had dystonic spasms associated with striatopallidal lesions and one with a thalamic and striatopallidal lesion. One other patient presented with a myoclonic dystonia related to a thalamic lesion. The striatopallidal lesions were located in the sensorimotor area with a somatotopical distribution. The pure thalamic lesion involved the centromedian nucleus, the sensory nuclei, and the pulvinar whereas the thalamic and striatopallidal lesion was located in the pallidonigral thalamic territory, which receives pallidonigral inputs. Conclusion-The striatopallidal dystonia might be the consequence of the interruption of the cortico-striato-pallidothalamo-cortical loop induced by lesions located within the sensorimotor part of the striatopallidal complex. By contrast, it is suggested that thalamic dystonia might be caused by lesions located in the centromedian or the ventral intermediate nuclei, outside the pallidonigral territory, but leading also to a dysfunction of the cortico-striato-pallido-thalamo-cortical loop.

(F Neurol Neurosurg Psychiatry 1998;65:703-708)
\end{abstract}

Keywords: dystonia; basal ganglia; thalamus; stroke

Focal brain lesions can induce several types of abnormal involuntary movements - for example, dystonia, chorea, hemiballism, tremor, myoclonus, parkinsonism, and asterixis. ${ }^{12}$ The most frequent cause is stroke, followed by tumour, trauma, anoxia, vascular malformation, or multiple sclerosis. ${ }^{12}$ For some causes such as stroke or anoxia these abnormal involuntary movements can occur immediately after the brain lesion (for example, hemiballism), ${ }^{3}$ when the initial motor deficit improves or recovers, or after a long period (a few months or years) of stability of the motor impairment. ${ }^{45}$ Among these abnormal involuntary movements, dystonia, which is particularly common, is often related to vascular lesions, usually located within the striatopallidal complex, ${ }^{4-11}$ the thalamus, ${ }^{410} 12-14$ or the brainstem. ${ }^{2}$ Most of the striatopallidal lesions are located in the lentiform nucleus, especially the putamen. ${ }^{4}$ With thalamic lesions, myoclonic dystonia is not commonly reported. ${ }^{10} 15$ Stroke can induce unique localised lesions with well defined boundaries that facilitate anatomical-clinical correlations but only a few neuropathological studies have been published. ${ }^{6}{ }^{12}{ }^{16}$ Furthermore it remains difficult to determine in vivo the exact localisation of the lesions because of the lack of precision of conventional radiology; indeed, most of the studies used CT and standard MRI, which could not specify exactly which striatopallidal area - sensorimotor or associativewas involved, or to what extent there was a somatotopical distribution of the lesion, or which thalamic nuclei were affected. ${ }^{12}$ Only Lehéricy et al has used methods similar to ours, ${ }^{10}$ one which allows a more precise approach to the location of lesions.

The aim of this study was to establish the pathophysiological mechanisms of striatopallidal and thalamic dystonia by establishing precise clinicoradiological correlations. This was facilitated by our recent knowledge on the circuitry of the basal ganglia. ${ }^{17}$ We chose therefore to study stroke patients with focal lesions. They underwent three dimensional T1 weighted MRI sequence (1.5 tesla) to determine the precise topography of lesions by stereotactic analysis using the atlas of Hassler. ${ }^{18}$ We then compared the lesions with clinical findings to clarify pathophysiological mechanisms.

\section{Patients and methods}

PATIENTS

Patients were selected according to the following criteria: all of them had presented with a stroke (infarct or haemorrhage) initially responsible for hemiplegia, followed by symptomatic dystonic spasms or myoclonic dystonia of delayed onset. Dystonic spasms were defined as sustained muscle contractions responsible for twisting and repetitive movements or abnormal postures, and were triggered by postures and increased by voluntary movements and gait, whereas they were absent at rest. ${ }^{19}$ Myoclonic dystonia consisted of sustained 
Table 1 Clinical features

\begin{tabular}{|c|c|c|c|c|c|}
\hline Patients & 1 & 2 & 3 & 4 & 5 \\
\hline Neurological signs at onset of lesion & Right hemiplegia & $\begin{array}{l}\text { Right hemiplegia } \\
\text { Aphasia }\end{array}$ & $\begin{array}{l}\text { Left hemiplegia and } \\
\text { sensory loss }\end{array}$ & $\begin{array}{l}\text { Right hemiplegia and } \\
\text { sensory loss Aphasia }\end{array}$ & Right hemiplegia \\
\hline Cause of dystonia & Infarct & Infarct & Haemorrhage & Infarct & Infarct \\
\hline Delay of onset of dystonia & 6 weeks & 4 months & 1 month & 3 months & 7 months \\
\hline Age at onset of dystonia & $39 \mathrm{y}$ & $52 \mathrm{y}$ & $66 \mathrm{y}$ & $33 \mathrm{y}$ & $50 \mathrm{y}$ \\
\hline Age at time of study & $43 \mathrm{y}$ & $73 \mathrm{y}$ & $72 \mathrm{y}$ & $34 \mathrm{y}$ & $57 \mathrm{y}$ \\
\hline Topography of dystonia & Hemidystonia & Hemidystonia & $\begin{array}{l}\text { Focal dystonia: } \\
\text { right hand }\end{array}$ & Focal dystonia: right foot & $\begin{array}{l}\text { Segmental dystonia: hand } \\
\text { and forearm }\end{array}$ \\
\hline Type & Dystonic spasms & Dystonic spasms & Myoclonic dystonia & Dystonic spasms & Dystonic spasms \\
\hline Neurological signs at time of study & None & Mild hemiparesis & Mild hemiparesis & Tactile sensory loss & $\begin{array}{l}\text { Spastic hypertonia of } \\
\text { lower limb }\end{array}$ \\
\hline
\end{tabular}

Table 2 Imaging results (the lesions are classified for each structure involved according to the ratio (\%) between the involved volume and the volume taken by the structure on the atlas of Hassler ${ }^{10}$ )

\begin{tabular}{|c|c|c|c|c|c|}
\hline Patients & 1 & 2 & 3 & 4 & 5 \\
\hline Lesion volume $\left(\mathrm{mm}^{3}\right)$ & 2863 & 899 & 109 & 1204 & 88 \\
\hline Putamen (\%) & $30(\mathrm{Pr}+\mathrm{Po} \mathrm{Com})$ & 3 (Po Com) & 0 & 50 (Po Com) & 2 (Po Com) \\
\hline $\mathrm{GPi}(\%)$ & 0 & 23 & 0 & 0 & 11 \\
\hline GPe (\%) & 41 & 17 & 0 & 32 & 12 \\
\hline Thalamus (\%) & 0 & 23 (RN: 68; VA: 28; VLa: 4) & 96 (CM-Pf: 76; VP: 13; Pv: 11) & 0 & 0 \\
\hline $\mathrm{CN}(\%)$ & 19 & 24 & 0 & 18 & 0 \\
\hline Others $(\%)$ & 10 (IC; EC; AC) & 10 (IC) & $4(\mathrm{HT})$ & 0 & 75 (IC) \\
\hline
\end{tabular}

$\mathrm{GPe}=$ external globus pallidus; $\mathrm{GPi}=$ internal globus pallidus; $\mathrm{CN}=$ caudate nucleus; $\mathrm{IC}=$ internal capsule; $\mathrm{AC}=$ anterior commissure; $\mathrm{HT}=$ hypothalamus; $\mathrm{EC}=$ external capsule; Pr Com=precommissural; Po Com=postcommissural; VA=ventral anterior nucleus; VLa=ventral lateral anterior nucleus; $\mathrm{RT}=$ reticular nucleus; $\mathrm{VP}=$ ventral posterior nucleus; $\mathrm{Pv}=$ pulvinar; $\mathrm{CM}-\mathrm{Pf}=$ centromedian-parafascicularis nucleus.

muscle contractions overlain by myoclonic jerks. ${ }^{20}$ Symptomatic dystonia was defined according to the following criteria: unilateral dystonia (contralateral to the vascular lesion), presence of additional neurological abnormalities, rapidly progressive evolution, and unusual course in terms of the distribution of parts of the body affected or age at onset. ${ }^{21}$ Dystonia affected the ipsilateral arm and leg (hemidystonia), two or more contiguous parts of the body (segmental dystonia), or a single part of the body (focal dystonia). ${ }^{19}$ According to CT and standard MRI, the lesions were located within the basal ganglia, or the thalamus, or both. Thus 26 consecutive patients were first retrospectively selected among patients admitted to the neurology departments of R Salengro Hospital, Lille between March 1987 and July 1996. Of this first group, four patients were lost to follow up. Two patients refused another MRI. Thirteen patients were excluded because of lesions with indefinite boundaries, or multiple

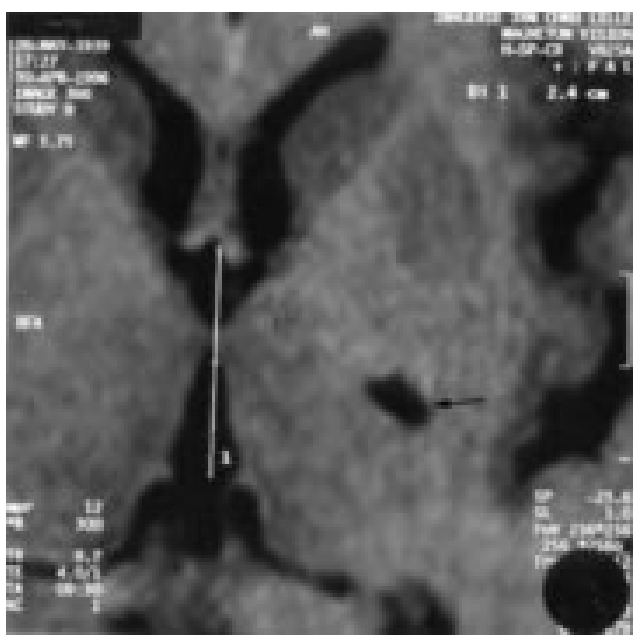

Figure 1 Three dimensional T1weighted MRI sequence $(M P-R A G E)$ : axial reconstruction according to the bicommissural line, showing the lenticular lesion; the bicommissural line is superimposed on the slice. or large brain lesions not suitable for precise radiological analysis.

Finally, seven patients had head MRI according to methods described later. Two of these seven patients were excluded because of a lesion with indefinite boundaries in one and artefacts due to abnormal involuntary movements in the second. The MRI of the five remaining patients - with a single localised vascular lesion-was analysed using Hassler's atlas. $^{18}$

\section{METHODS}

Imaging was performed with a 1.5 tesla MR unit (Siemens Vision, Erlangen) and standard head coil. A 3D T1 weighted MP-RAGE sequence $(\mathrm{TR}=9.7 \mathrm{~ms} ; \mathrm{TE}=4 \mathrm{~ms}$; TI=300 ms; field of view $=256 \mathrm{~mm}$; matrix $=256 \times 256$; two acquisitions) was used, allowing $1 \mathrm{~mm}$ isometric pixel size. After acquisition, data were analysed and reconstructed on a Siemens workstation using Numaris V 4.3 software. The bicommissural plane on the midsagittal slice was identified and $1 \mathrm{~mm}$ contiguous axial slices were reconstructed. Afterwards, sagittal and coronal planes were defined from the bicommissural plane and $1 \mathrm{~mm}$ contiguous slices were reconstructed. On magnified images, bicommissural distance was defined as the shortest distance between opposing surfaces of the commissures. ${ }^{18}$ The middle of the bicommissural line was used to specify three dimensional lesion coordinates for each plane and slice. Then, measures were manually reported on Hassler's atlas according to bicommissural length, width of the third ventricle, and thalamus size..$^{18}$ Boundaries of each lesion were reconstructed on Hassler's atlas on axial, coronal, and sagittal planes to determine the different structures involved and to assess the lesion volume. Thalamus segmentation was studied according to the classification of Hirai and Jones, which is commonly used and provides a good definition of thalamic physiological territories. ${ }^{22}$ 


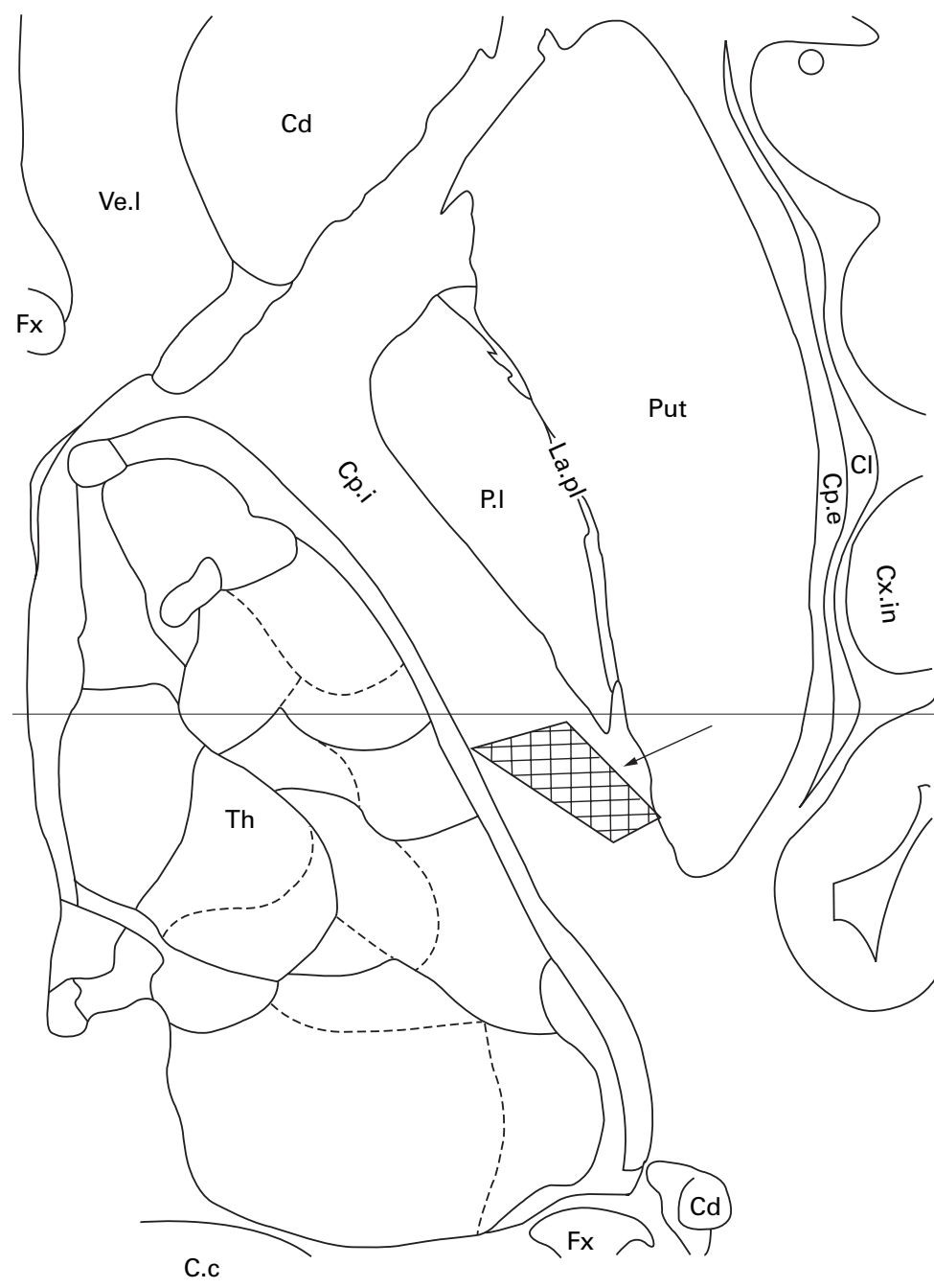

Figure 2 Lesion coordinates (axial reconstruction) are superimposed on the atlas of Hassler. $C . c=$ corpus callosum; $C d=$ caudate nucleus; $C l=$ claustrum; $C p . e=$ external capsule, Cp. $i=$ internal capsule; $C x$. in=insular cortex; $F x=$ fornix; La.p.l=lamina pallidi lateralis; P.l=globus pallidus externus; Put=putamen; Th=thalamus; Ve.l=lateral ventricle.

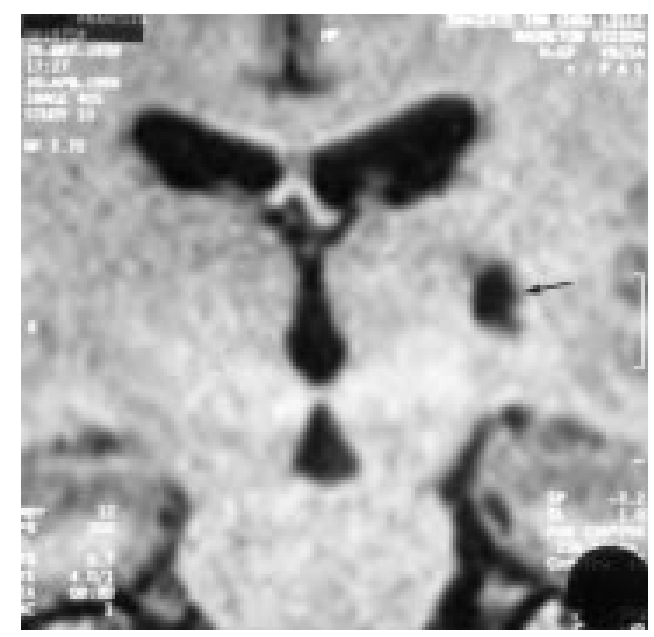

Figure 3 Three dimensional T1 weighted MRI sequence $(M P-R A G E)$ : coronal reconstruction according to the bicommissural line, showing the lenticular lesion.

\section{Results}

CLINICAL FINDINGS

Clinical features of the patients (four women and one man), all right handed, are summarised in table 1. Mean age at the time of the study was
55.8 years. Causes of dystonia were either haemorrhage (patient 3), or infarcts (other patients). The interval between stroke and onset of dystonia varied from 6 weeks (patient 1) to 7 months (patient 5) (mean 3.2 months). Dystonia occurred when patients had almost or completely recovered from hemiplegia.

Patients 1, 2, 4, and 5 presented with dystonic spasms whereas patient 3 presented with myoclonic dystonia. There were two cases of hemidystonia (patients 1 and 2), one case of segmental dystonia (patient 5), and two cases of focal dystonia (patient 3, hand; patient 4, foot). Patient 1 had extension of the fingers, pronation of the forearm, and sometimes abduction and external rotation of the arm. There was also a hyperextension of the big toe alternating with a flexion of the other toes and equine varus attitude of the foot. Patient 2 had internal rotation of the arm, hyperextension of the wrist and of the metacarpophalangeal joints, adduction of the thumb and the hand, and equinovarus foot. Patient 4 had hyperextension of the big toe and adduction of the second and third toes. Patient 5 had dystonic deep hand, flexion of the fingers, and pronation of the forearm. Patient 3 had flexion and pronation of the hand and superimposed distal and proximal myoclonic jerks.

At the time of the study, patients 2, 3, 4, and 5 had sequelae from stroke: mild hemiparesis with Babinski's sign and hyperreflexia (patient 2 and 3), tactile hemihypoaesthesia, (patient 4) and spastic hypertonia of the lower limb with hyperreflexia (patient 5).

\section{IMAGING RESULTS}

Imaging results are summarised in table 2 and are illustrated from patient 5 in figs 1-4; figs 1 and 2 show respectively the axial reconstruction according to the bicommissural line and the report on Hassler's atlas and figs 3 and 4 show the coronal reconstruction and the report on the atlas. ${ }^{18}$ Estimated volume of lesions varied from $88 \mathrm{~mm}^{3}$ to $2863 \mathrm{~mm}^{3}$ (mean $1032 \mathrm{~mm}^{3}$ ). Lesions were hypointense on $\mathrm{T} 1$ weighted images, which provided good delineation of boundaries. Bicommissural distance (23 to 29 $\mathrm{mm}$; mean, $25.2 \mathrm{~mm}$ ) was in accordance with the measures of Schaltenbrand performed on 111 brains for the atlas. ${ }^{18}$ Three patients $(1,4$, and 5) had lesions located exclusively within the striatopallidal complex. Patient 2 presented with both thalamic and striatopallidal lesions. Patient 3 had a pure thalamic lesion. The postcommissural part of the putamen was predominantly affected (except patient 1: precommissural and postcommissural putamen), as was the head and body of the caudate nucleus (except patient 5). In two patients (1 and 4 ), the lesions were located in the putamen with a somatotopical distribution; for the segmental dystonia of the upper limb (patient 4) and the hemidystonia (patient 1), putaminal lesions involved the somatotopic area corresponding respectively to the upper limb and both upper and lower limbs. ${ }^{23}$ The internal pallidum and external pallidum were similarly involved in patients 2 and 5 whereas only the external pallidum was affected in patients 1 and 4 . The tha- 


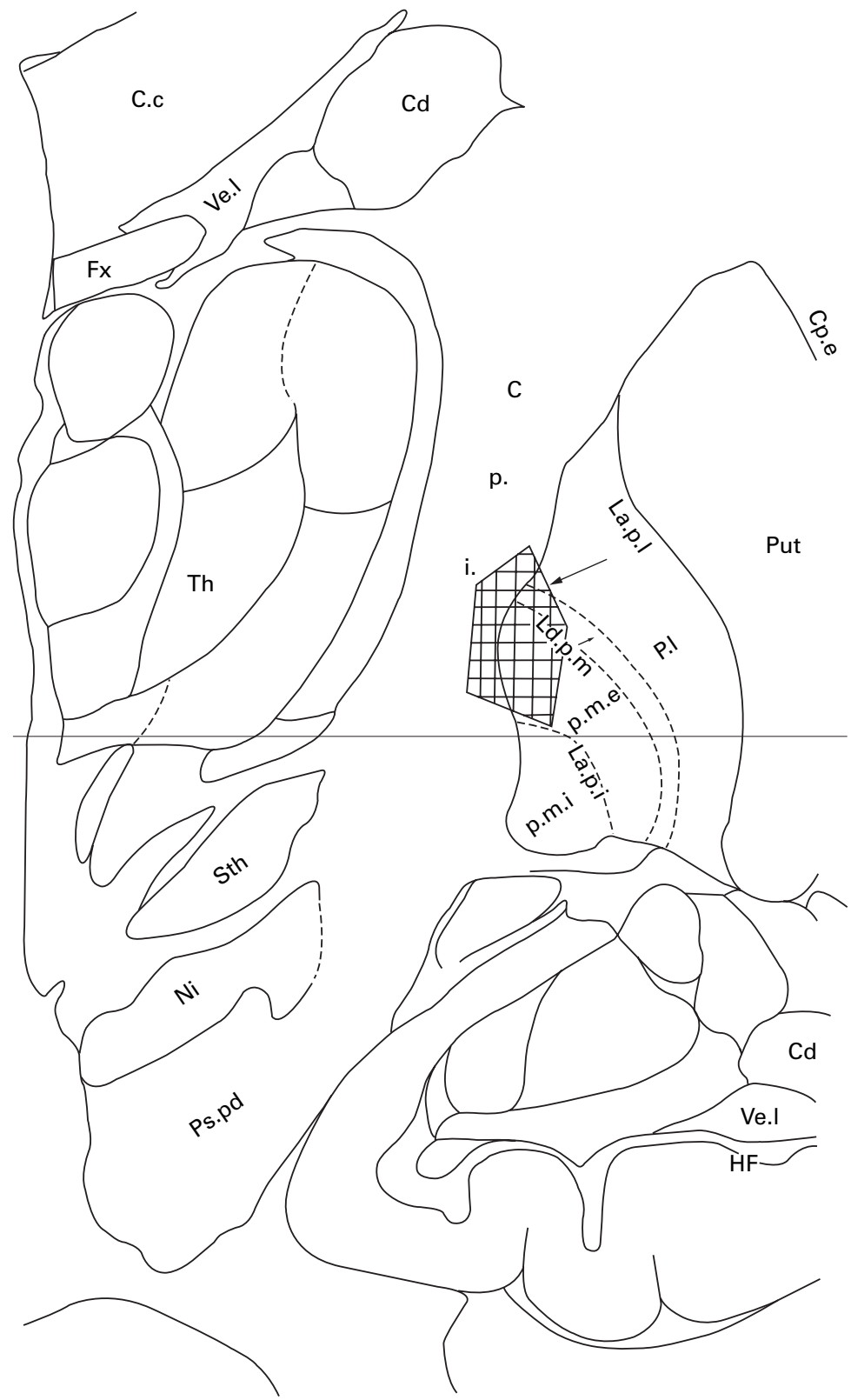

Figure 4 Lesion coordinates (coronal reconstruction) are superimposed on the atlas of Hassler. $C . c=$ corpus callosum; $C d=$ caudate nucleus; $C p . e=$ external capsule; $C p . i=$ internal capsule; $F x=$ fornix; $H F=$ hippocampal formation; La.p. $i=$ lamina pallidi incompleta La.p.l=lamina pallidi lateralis; La.p.m=lamina pallidi medialis; $\mathrm{Ni=substantia} \mathrm{nigra;}$ $P . l=$ globus pallidus externus; $P . m . e=$ globus pallidus internus pars lateralis; $P . m . i=$ globus pallidus internus pars medialis; Ps.pd=cerebral peduncle, pars superior; Put=putamen;

Th=thalamus; Sth=subthalamic nucleus; Ve.l=lateral ventricle.

lamic lesion in patient 2 involved a part of the pallidonigral territory (ventral anterior nucleus; ventral lateral anterior nucleus). For the pure thalamic lesion (patient 3), the centromedianparafascicularis nucleus, the pulvinar, and the sensory nuclei (ventral posterior lateral nucleus; ventral posterior medial nucleus; ventral medial basal nucleus) were affected.

\section{Discussion}

Our study has shown that a three dimensional T1 weighted MRI associated with a stereotactic analysis using Hassler's atlas, ${ }^{18}$ provided precise clinicoradiological correlations. Our MRI technique is clearly better than CT and standard MRI. It allows excellent contrast so that valuable delineation of the basal ganglia is possible, and provides precise localisation of the lesions despite some factors which limit its precision (an order of $\mathrm{mm}$ ) ${ }^{24-26}$ Indeed, reconstructions based on Hassler's atlas can pose difficulties regarding the localisation of the lesions: (1) the atlas is based on a single brain for each plane, and does not take into account anatomical variations; (2) the interslice space varies according to the situation of the slice in relation to the centre of the bicommissural plane, and furthermore, the axial plane cannot be used because of an angle of $7^{\circ}$ with the bicommissural plane ${ }^{27}$; (3) our method provided only rigid transformations, which consisted of translation or rotation of reconstructed boundaries, so that complicated deformations could not be taken into consideration. ${ }^{27}{ }^{28} \mathrm{Com}$ puterised methods using elastic deformations would have given better results. ${ }^{28-31}$ However, this problem did not influence our study because these patients had small lesions inducing only moderate displacements.

For the patients with striatopallidal lesions, patients 2, 4, and 5 had lesions located within the postcommissural putamen, which is included in the sensorimotor part of the striatum, whereas patient 1 had a lesion located within the postcommissural and precommissural putamen, which is included in the associative part of the striatum. ${ }^{32}$ Moreover, the lateral and ventral part of the head of the caudate nucleus, which is a sensorimotor part of the striatum, ${ }^{33}$ was affected in patients 1,2 , and 4. Our results, and suggestions by others, ${ }^{10} 34$ indicate that the sensorimotor part of the striatum plays an important part in the induction of dystonia. However, cases of dystonia induced by pure lesions of the caudate nucleus are rare, ${ }^{45}$ and we think that this may be due to the fact that the sensorimotor area of the caudate nucleus remains unaffected in most cases because of its very restricted size. The findings from patients 1 and 4 suggested a somatotopical distribution within the sensorimotor putamen, also mentioned in an earlier report. ${ }^{10}$ For patients 2 and 5, the lesion was somatotopically located in the face area of the putamen ${ }^{23}$; however, given the fact that dystonia involved both the upper and lower limbs in patient 2 , and the upper limb alone in patient 5 , this could possibly be due to the somatotopical organisation of the pallidal lesion. We were unable to determine if the sensorimotor part of the pallidum was also predominantly affected (with or without a somatotopical distribution) in our patients as the sensorimotor and associative areas in the pallidum are usually less well defined than in the putamen. ${ }^{33}$

As has already been suggested, ${ }^{14}$ putaminal lesions might interrupt both direct and indirect pathways. ${ }^{36}$ The underactivity of the indirect pathway might predominate and this disruption could increase the thalamocortical drive and induce dystonia. The experiments of Mitchell et al are partially in agreement with this hypothesis: there was underactivity of the indirect pathway but increased activity of the direct pathway. ${ }^{37}$ Both hypotheses lead to the same conclusion: dystonia could be induced by an increased thalamocortical drive. In cases of 
putaminal lesions, there could be an interruption of the cortico-striato-pallido-thalamocortical loop. This is backed up by a recent PET study in acquired hemidystonia due to striatopallidal lesions ${ }^{38}$ : there was an increased activity in cortical motor areas, both receiving inputs from the pallidonigral thalamic territory. This is in agreement with our four patients, who had lesions in the lentiform nuclei and especially in the putamen (patients 1 and 4). The pallidal involvement (especially the external pallidum, as the internal globus pallidum was spared in patients 1 and 4 ) in our three patients $(1,4,5)$ could also play a part in the induction of dystonia, as has been reported in humans and monkeys. ${ }^{139}{ }^{40}$ We suggest that dystonia can be induced by increased thalamocortical drive due to an interruption of the cortico-striato-pallido-thalamo-cortical loop by lesions located in the sensorimotor part of the striatopallidal complex and not by putaminal lesions alone.

In patient 2, we think that the thalamic lesion, located within the pallidonigral territory (ventral nucleus, ventral lateral anterior nucleus), ${ }^{22}$ cannot induce dystonia for several reasons: firstly, if we take into account the increased thalamocortical drive hypothesis, a lesion of the thalamic pallidonigral territory should suppress dystonia by an inhibition of the thalamocortical drive overactivity rather than inducing it, although paradoxically the surgical treatment of dystonia uses a stereotactic target located outside the pallidonigral territory (thalamotomy or chronic thalamic stimulation) ${ }^{42-44}$ Also, to our knowledge, there is no reported case of thalamic dystonia associated with a vascular lesion located within the polar artery territory (including the pallidonigral territory). This may suggest that striatopallidal dystonia and thalamic dystonia have different pathophysiological bases, although both induce overactivity in motor areas. ${ }^{38}$ Thalamic dystonia would be associated with lesions located outside the pallidonigral territory.

In patient 3 with a pure thalamic lesion, the pallidonigral territory was spared, ${ }^{2241}$ as also noted in the patients described by Lehéricy et $a l .^{10}$ This suggests that physiopathology of dystonia in these cases is different from that with striatopallidal lesions. A large part of the lesion was located in the centromedical nucleus (CM) (essential regulator of the cortico-striatopallido-thalamo-cortical loop), ${ }^{36}$ as in the four patients described by Lehéricy et al. ${ }^{10}$ We think that it could play an important part in the induction of dystonia. This hypothesis is supported by experiments which suggest an inhibiting role of the mesial thalamus (including the $\mathrm{CM}$ ) on the ventral lateral nucleus, which receives pallidal inputs. ${ }^{45} \mathrm{~A}$ PET study, in which overactivity was seen in motor areas after thalamic lesions, ${ }^{38}$ is in agreement with the increased thalamocortical drive hypothesis. Moreover, the experiments of Mitchell et al suggest that the CM could also induce dystonia by lesion of the inputs from the pedunculopontine complex. ${ }^{37}$ Given topographical errors due to methods (methods allow $1 \mathrm{~mm}$ thin sections minimising partial voluming and multiplanar reconstruction), ${ }^{10}$ and given involvement of sensory nuclei, ${ }^{22}$ the ventral intermediate nucleus of Hassler $^{18}$ (ventral part of ventral lateral posterior nucleus of Hirai and Jones ${ }^{22}$ ), which is very close to the ventral posterior nucleus, could also be affected and play a part in the induction of dystonia although it was seemingly spared: the ventral intermediate nucleus was involved in all patients of Lehéricy et $a l^{10}$; dystonia can also be induced by lesions of the cerebellar pathways which pass through the ventral intermediate nucleus, ${ }^{46}$ as has already been reported in humans, ${ }^{47-50}$ and animal experiments. ${ }^{51-53} \mathrm{Fi}-$ nally, the primary and accessory motor areas receive inputs from both thalamic pallidal and thalamic cerebellar territories, ${ }^{33}$ and a PET study in acquired hemidystonia induced by thalamic lesions disclosed an increased activity in motor areas. ${ }^{38}$ The pulvinar was affected, as in two patients ( 5 and 6 ) described by Lehéricy et $a l,{ }^{10}$ but was not involved in patients 7 and 8 of their series. Thus, it seems unlikely that this nucleus is responsible for dystonia. The last nuclei affected were the sensory nuclei (ventral posterior lateral nucleus, ventral posterior medial nucleus, ventral medial basal nucleus) also mentioned by Lehéricy et al. ${ }^{10}$ However, the PET study mentioned above did not display variations of activity in cortical sensory areas (receiving inputs from the thalamic sensory territory). ${ }^{38}$ Thus it is unlikely that the sensory nuclei can induce dystonia.

Therefore, thalamic dystonia and striatopallidal dystonia might not share the same physiopathological bases but might both lead to a dysfunction of the cortico-striato-pallidothalamo-cortical loop leading to an overactivity in primary and accessory motor areas. Whether an isolated lesion of the CM or the ventral intermediate nucleus, or a lesion affecting both, can induce dystonia, remains unknown. Furthermore, we still do not know why lesions located in similar areas may not necessarly cause dystonia.

1 Bhatia KP, Marsden CD. The behavioural and motor consequences of focal lesions of the basal ganglia in man. Brain 1994;117:859-76.

2 Lee MS, Marsden CD. Movement disorders following lesions of the thalamus or subthalamic region. Mov Disord 1994;9:493-507.

3 Destée A, Muller JP, Vermersch P, et al. Hémiballisme. Hémichorée. Infarctus striatal. Rev Neurol 1990;146:150-2.

4 Marsden CD, Obeso JA, Zarranz JJ, et al. The anatomical basis of symptomatic hemidystonia. Brain 1985;108:46383.

5 Scott BL, Jankovic J. Delayed-onset progressive movement disorders after static brain lesions. Neurology 1996;46:6874 .

6 Dooling EC, Adams RD. The pathological anatomy of postDooling EC, Adams RD. The pathological a
hemiplegic athetosis. Brain 1975;98:29-48.

7 Burke RE, Fahn S, Gold AP. Delayed-onset dystonia in Burke RE, Fahn S, Gold AP. Delayed-onset dystonia in
patients with static encephalopathy. $\mathscr{f}$ Neurol Neurosurg Psychiatry 1980;43:789-97.

8 Burton K, Farrell K, Li D, et al. Lesions of the putamen and dystonia: CT and magnetic resonance imaging. Neurology 1984;34:962-5

9 Grimes JD, Hassan MN, Quarrington AM, et al. Delayedonset posthemiplegic dystonia: CT demonstration of basal ganglia pathology. Neurology 1982;32:1033-5.

10 Lehéricy S, Vidailhet $M$, Dormont $\mathrm{D}$, et al. Striatopallidal and thalamic dystonia: a magnetic resonance imaging anatomoclinical study. Arch Neurol 1996;53:241-50.

11 Pettigrew LC, Jankovic J. Hemidystonia: a report of 22 patients and a review of the literature. $\mathcal{F}$ Neurol Neurosurg Psychiatry 1985;48:650-657.

12 Garcin R. Syndrome cérébello-thalamique par lésion localisée du thalamus avec une digression sur le "signe de la main creuse" et son intérét séméiologique. Rev Neurol 1955;93:143-9.

13 Berkovic SF, Bladin PF. Rubral tremor: clinical features and treatment of three cases. Clin Exp Neurol 1984;20:119-28. 
14 Dewey RB, Jankovic J. Hemiballism-hemichorea. Clinical and pharmacological findings in 21 patients. Arch Neurol and pharmacolo

15 Ghika J, Bogousslavsky J, Henderson J, et al. The jerky dystonic unsteady hand: a delayed motor syndrome in posterior thalamic infarctions. $\mathcal{F}$ Neurol 1994;241:537-42.

16 Oppenheimer DR. A case of striatal hemiplegia. $\mathcal{F}$ Neurol Neurosurg Psychiatry 1967;30:134-9.

17 Alexander GE, De Long MR, Strick PL. Parallel organization of functionally segregated circuits linking basal ganglia and cortex. Anпu Rev Neurosci 1986;9:357-81.

18 Hassler R. Architectonic organization of the thalamus In: Schaltenbrand G. Atlas for stereotaxy of the human brain. Stuttgart: Georg Thieme Verlag, 1977.

19 Fahn S. Concept and classification of dystonia. Adv Neurol 1988;50:1-8.

20 Obeso JA, Rothwell JC, Lang AE, et al. Myoclonic dystonia. Neurology 1983;33:825-30.

21 Fahn S, Marsden CD, Calne DB. Classification and investigation of dystonia. In: Marsden CD, Fahn S, eds. Movement gation of dystonia. In: Marsden CD, Fahn S, eds.

22 Hirai T, Jones EG. A new parcellation of the human thalamus on the basis of histochemical staining. Brain Res Rev 1989;14:1-34.

23 Künzle H. Bilateral projections from precentral motor cortex to the putamen and other parts of the basal ganglia. Brain Res 1975;88:195-209.

24 Dormont D, Zerah M, Cornu P. A technique of measuring the precision of MR guided stereotaxic installation using anatomic specimens. Am f Neuroradiol 1994;15:365-71.

25 Villemure JG, Marchand E, Peters T, et al. Magnetic resonance imaging stereotaxy: recognition and utilization of commissures. Appl Neurophysiol 1987;50:57-62.

26 Yoshida $M$. Creation of a three dimensional atlas by interpolation from Shaltenbrand-Bailey's atlas. Appl Neurophysiol 1987;50:45-8.

27 Nieman K, Naujokat C, Pohl G, et al. Verification of the Schaltenbrand and Wahren stereotactic atlas. Acta Neurochi. 1994;129:72-81.

28 Greitz T, Bohm C, Holte S, et al. A computerized brain atlas: constructions, anatomical content and some applicaatlas: constructions, anatomical content and som

29 Dann R, Hoford J, Kovasic S, et al. Evaluation of elastic matching system for anatomic (CT, MR) and functional (PET) cerebral images. F Comput Assist Tomogr 1989;13 603-11

30 Gee JC, Reivich M, Bajcsy R. Elastically deforming 3D atlas to match anatomical brain images. $\mathcal{F}$ Comput Assist Tomogr 1993;17:225-36.

31 Toga AW. A digital three-dimensional atlas of structure function relationships. f Chem Neuroanat 1991;4:313-8.

32 Parent A. Extrinsic connections of the basal ganglia. Trend in Neuroscience 1990;13:254-8.

33 Percheron G, Yelnik J, Francois C, et al. Analyse informationnelle du systéme lié aux ganglions de la base. Rev Neurol 1994;150:614-26.

34 Narbona J, Obeso Ja, Tunon T, et al. Hemi-dystonia secondary to localised basal ganglia tumour. $\mathcal{F}$ Neurol Neurosurg ary to localised basal gan

35 Messimy R, Diebler C, Metzger J. Dystonie de torsion du membre supérieur gauche probablement consécutive à un traumatisme cranien. Rev Neurol 1977;133:199-206.
36 Flaherty AW, Graybiel AM. Anatomy of the basal ganglia. In: Marsden CD, Fahn S, eds. Movement Disorders 3. Chichester: Butterworth Heinemann, 1994:3-27.

37 Mitchell IJ, Luquin R, Boyce S, et al. Neural mechanisms of dystonia: evidence from a 2-deoxyglucose uptake study in a primate model of dopamine agonist-induced dystonia. Mov Disord 1990;5:49-54

38 Ceballos-Baumann AO, Passingham RE, Marsden CD, et al. Motor reorganization in acquired hemidystonia. Ann Neurol 1995;37:746-57.

39 Mink JW, Thach WT. Basal ganglia motor control. III. Pallidal ablation: normal reaction time, muscle cocontraction, and slow movement. F Neurophysiol 1991;65:330-51.

40 Kato M, Kimura M. Effects of reversible blockade of basal ganglia on a voluntary arm movement. If Neurophysiol 1992;68:1516-34.

41 Percheron G, Francois C, Talbi B, et al. The primate motor thalamus analyzed with reference to subcortical afferent territories. Stereotact Funct Neurosurg 1993;60:32-41.

42 Cooper IS. Twenty year follow up study of the neurosurgical treatment of dystonia musculorum deformans. In: Eldridge R, Fahn S, eds. Dystonia: advanced neurology. Vol 14. New York: Raven, 1976:423-52.

43 Tasker RR, Doorly T, Yamashiro K. Thalamotomy in generalized dystonia. In: Fahn S, Marsden CD, Calne DB, eds. Dystonia 2: advanced neurology. Vol 50. New York: Raven, 1988:615-31.

44 Sellal F, Hirsch E, Barth P, et al. A case of symptomatic hemidystonia improved by ventroposterolateral thalamic electrostimulation. Mov Disord 1993;4:515-18.

45 Milhorat TH. Exerimental myoclonus of thalamic origin. Arch Neurol 1967;17:365-78.

46 Ohye C, Shibazaki T, Hirai T, et al. Further physiological observations on the ventralis intermedius neurons in the human thalamus. F Neurophysiol 1989;61:488-500.

47 Gibb WRG, Lees AJ, Marsden CD. Pathological report of four patients presenting with cranial dystonias. Mov Disord 1988;3:211-21.

48 Day TJ, Lefroy RB, Mastaglia FL. Meige's syndrome and palatal myoclonus associated with brain stem stroke. A common mechanism ? f Neurol Neurosurg Psychiatry 1986; 49:1324.

49 Lang AE, Sharpe JA. Blepharospasm associated with palatal myoclonus and communicating hydrocephalus. Neurology 1984;34:1522-623.

50 Plant GT, Kermode AG, Du Boulay EPGH, et al. Spasmodic torticollis due to midbrain lesion in a case of multiple sclerosis. Mov Disord 1989;4:359-62.

51 Carpenter MB. A study of the red nucleus in the rhesus monkey. Anatomical degenerations and physiological effects resulting from localised lesions of the red nucleus. $\mathcal{F}$ Comp Neurol 1956;105:195-249.

52 Carrea RME, Mettler FA. Anatomy of primate brachium conjunctivum and associated structures. 7 Comp Neurol 1954;101:565-689.

53 Foltz EL, Knopp LM, Ward AA. Experimental spasmodic torticollis. F Neurosurg 1959;16:55-72. 